\title{
EUROfusion
}

\section{Structural assessment of the EU-DEMO WCLL Central Outboard Blanket Segment under normal and off-normal operating conditions}

\author{
I. Catanzaro ${ }^{a}$, P. Arena ${ }^{b}$, G. Bongiovìc, P. Chiovaroa, A. Del Nevo ${ }^{b}$, P.A. Di Maio ${ }^{a}$, R. Forte ${ }^{a}$, I.A. Maione ${ }^{c}$, E. Vallone $^{a}$
}

aDepartment of Engineering, University of Palermo, Palermo, Italy

bENEA CR Brasimone, Camugnano, Italy

cKarlsruhe Institute of Technology (KIT), Institute for Neutron Physics and Reactor Technology (INR), Hermann-von-Helmholtz-Platz 1, 76344 EggensteinLeopoldshafen, Germany

ilenia.catanzaro@unipa.it

\section{Abstract}

Within the framework of the EUROfusion design activities concerning the EU-DEMO Breeding Blanket (BB) system, a research campaign has been carried out at the University of Palermo with the aim of investigating the structural behaviour of the DEMO Water-Cooled Lithium Lead (WCLL) Central Outboard Blanket (COB) segment. The assessment has been performed considering three different loading scenarios: the Normal Operation (NO), the Over-Pressurization (OP) and the Vertical Displacement Event up (VDE-up). In particular, NO scenario represents the loading case referring to the nominal operating conditions, whereas the OP scenario refers to the loading conditions due to an in-box LOCA accident, listed as one of the BB design basis accidental events. Lastly, the VDE-up scenario is an off-normal event reproducing the plasma disruption caused by an uncontrolled vertical motion of the plasma volume. This event brings the plasma in contact with the upper walls, generating a sudden energy discharge accompanied by relevant electromagnetic (EM) forces on the structure. The study has been conducted following a theoreticalnumerical approach based on the Finite Element Method (FEM) and adopting the quoted ABAQUS v. 6.14 commercial FEM code. In particular, a detailed 3D FEM model of the whole COB segment, including the back-supporting structure and its attachment system to the vacuum vessel, has been set up. Several simulations have been carried out to assess the thermo-mechanical performances of the segment under the afore-mentioned loading scenarios, taking into account also the impact of the W-armour on the overall structural response. The structural integrity assessment has been also evaluated in view of the RCC-MRx structural design rules.

\section{Central Outboard Blanket segment model}

3D FEM model of the WCLL Central Outboard Blanket segment has been set-up. Moreover, with the aim of studying the impact of the tungsten on the thermomechanica behavior of the structure, two different models have been performed.

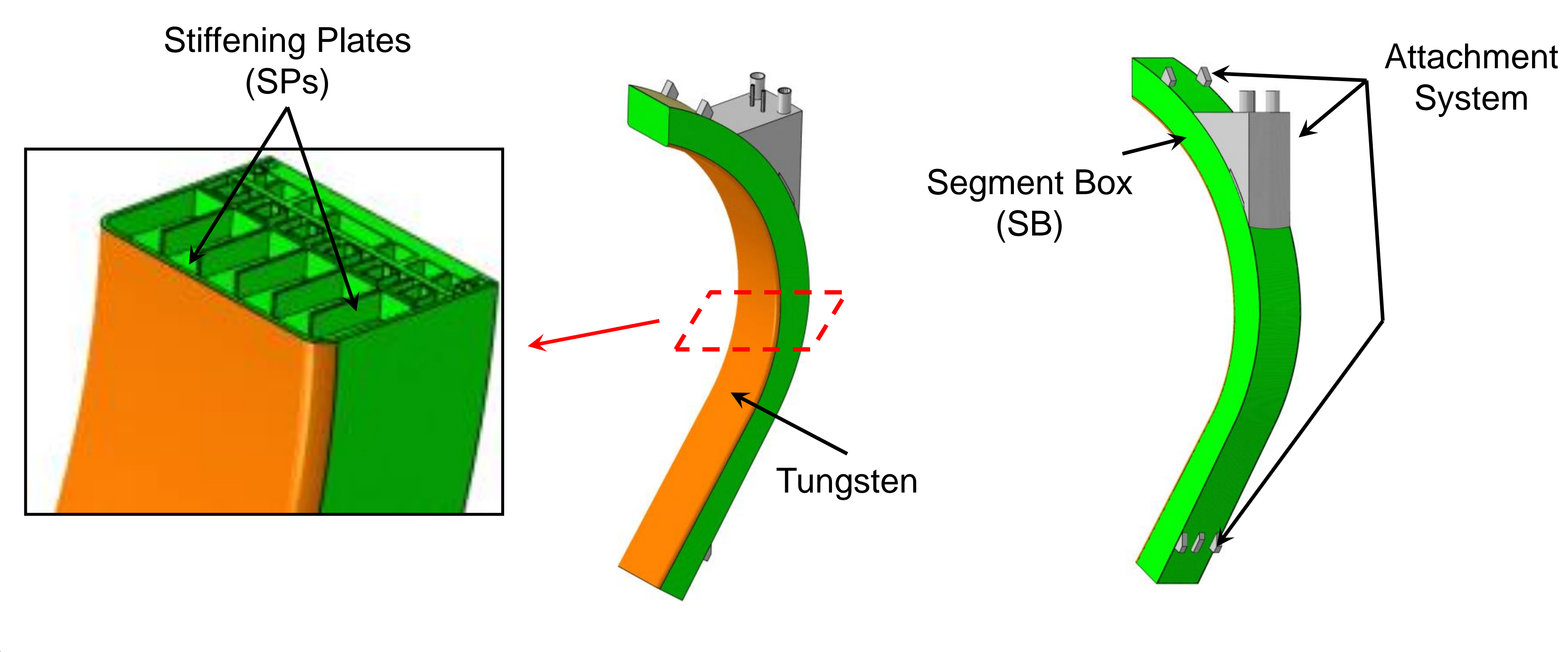

\section{Thermo-mechanical loads and boundary conditions}

Finite Element model composed of $\sim 2.3 \mathrm{M}$ nodes connected in $\sim 4.6 \mathrm{M}$ tetrahedral and hexahedral linear elements. The loading conditions concerning NO, OP and VDE-up scenarios have been considered in order to investigate the COB segment thermomechanical behavior.

\begin{tabular}{|c|c|c|c|}
\hline & NO scenario & OP scenario & VDE-up scenario \\
\hline $\begin{array}{l}\text { Non-uniform thermal } \\
\text { deformation field }\end{array}$ & $\begin{array}{l}\text { Imposed thermal field } \\
\text { drawn from reference } \\
\text { WCLL COB Equatorial } \\
\text { Region analysis }\end{array}$ & $\begin{array}{l}\text { Imposed thermal field } \\
\text { drawn from reference } \\
\text { WCLL COB Equatorial } \\
\text { Region analysis }\end{array}$ & $\begin{array}{l}\text { Imposed thermal field } \\
\text { drawn from reference } \\
\text { WCLL COB Equatorial } \\
\text { Region analysis }\end{array}$ \\
\hline Pressure & $\begin{array}{l}17.825 \mathrm{MPa} \text { on the } \\
\text { coolant-wetted surfaces } \\
0.575 \mathrm{MPa} \text { on the } \\
\text { breeder-wetted surfaces }\end{array}$ & $\begin{array}{l}\text { - } 17.825 \mathrm{MPa} \text { on the } \\
\text { coolant-wetted surfaces } \\
\text { - } 17.825 \mathrm{MPa} \text { on the } \\
\text { breeder-wetted surfaces }\end{array}$ & $\begin{array}{l}\text { - } 17.825 \mathrm{MPa} \text { on the } \\
\text { coolant-wetted surfaces } \\
0.575 \mathrm{MPa} \text { on the } \\
\text { breeder-wetted surfaces }\end{array}$ \\
\hline Gravity load & Gravity acceleration & Gravity acceleration & Gravity acceleration \\
\hline $\begin{array}{l}\text { Electro-Magnetic (EM) } \\
\text { loads }\end{array}$ & & & $\begin{array}{l}\text { - Maxwell's forces } \\
\text { - Lorentz's forces }\end{array}$ \\
\hline Mechanical restraints & COB attachment system & COB attachment system & COB attachment system \\
\hline
\end{tabular}
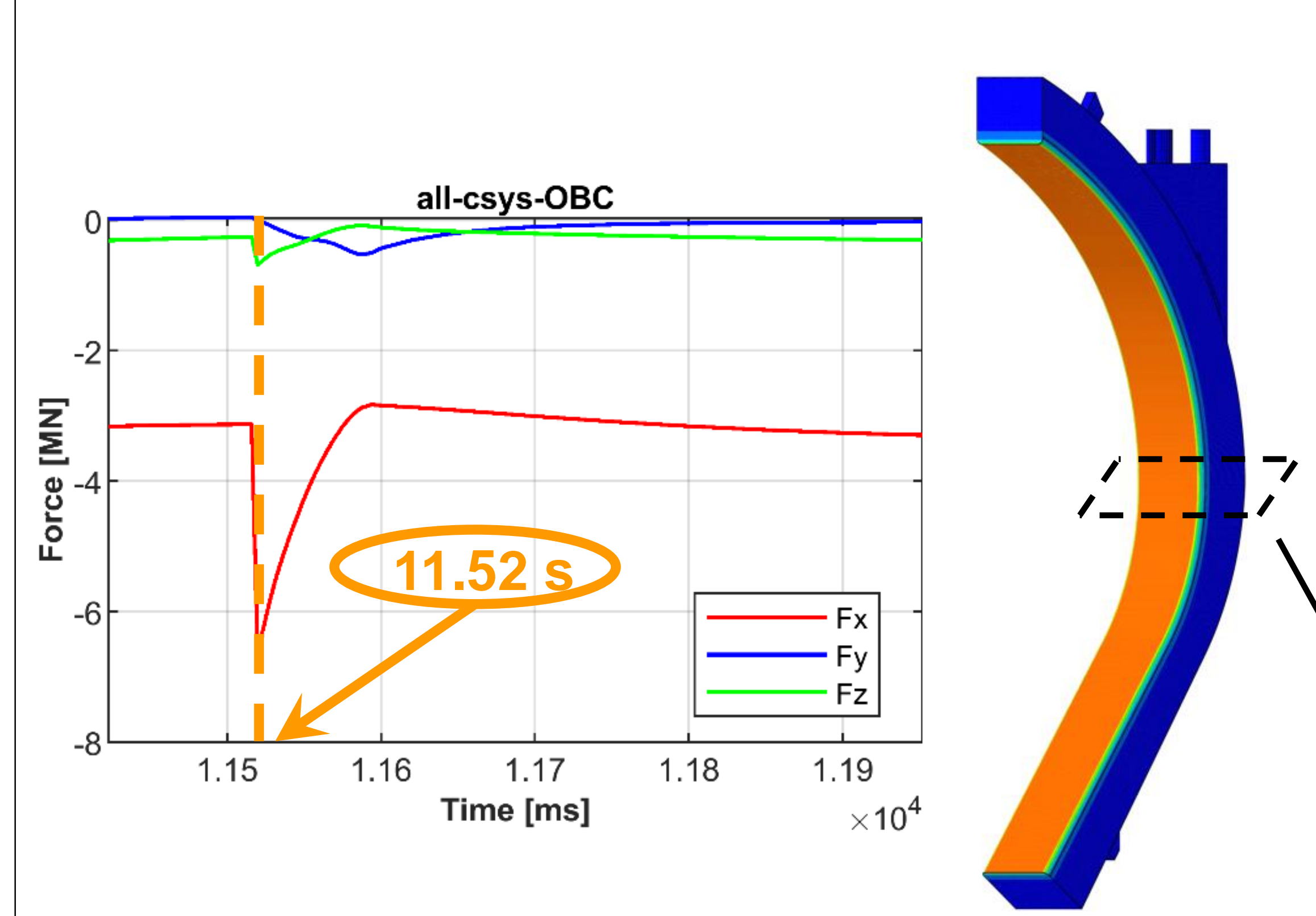

- Original thermal field

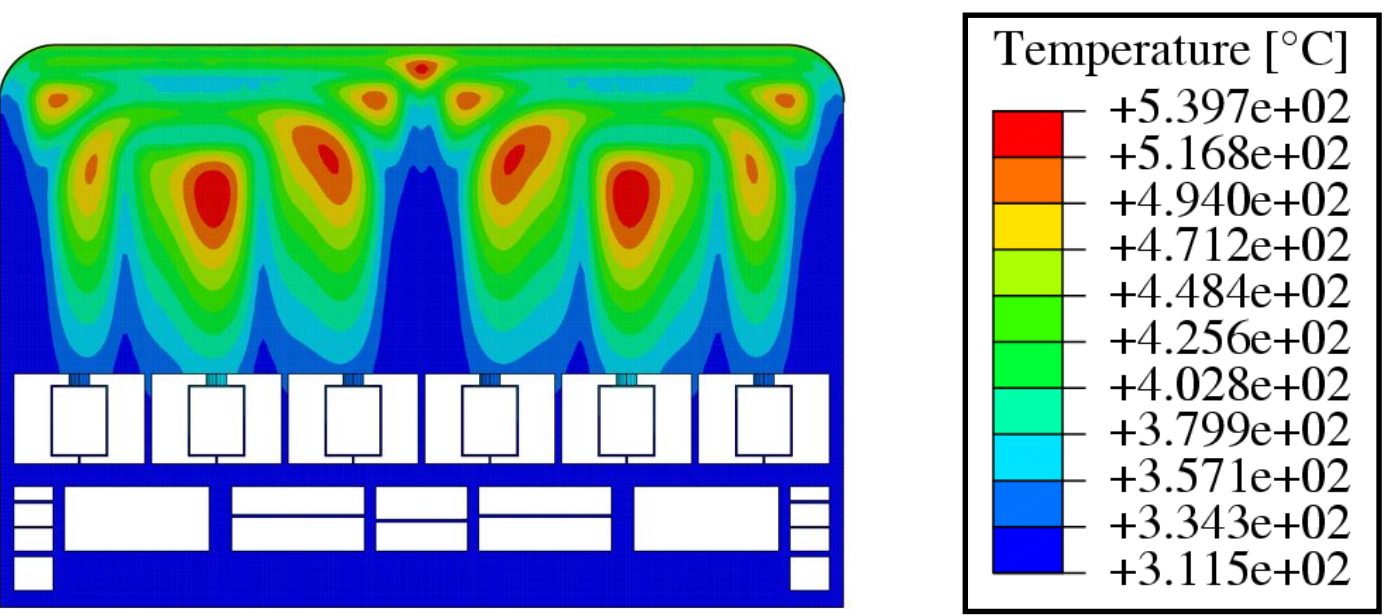

- Interpolated thermal field

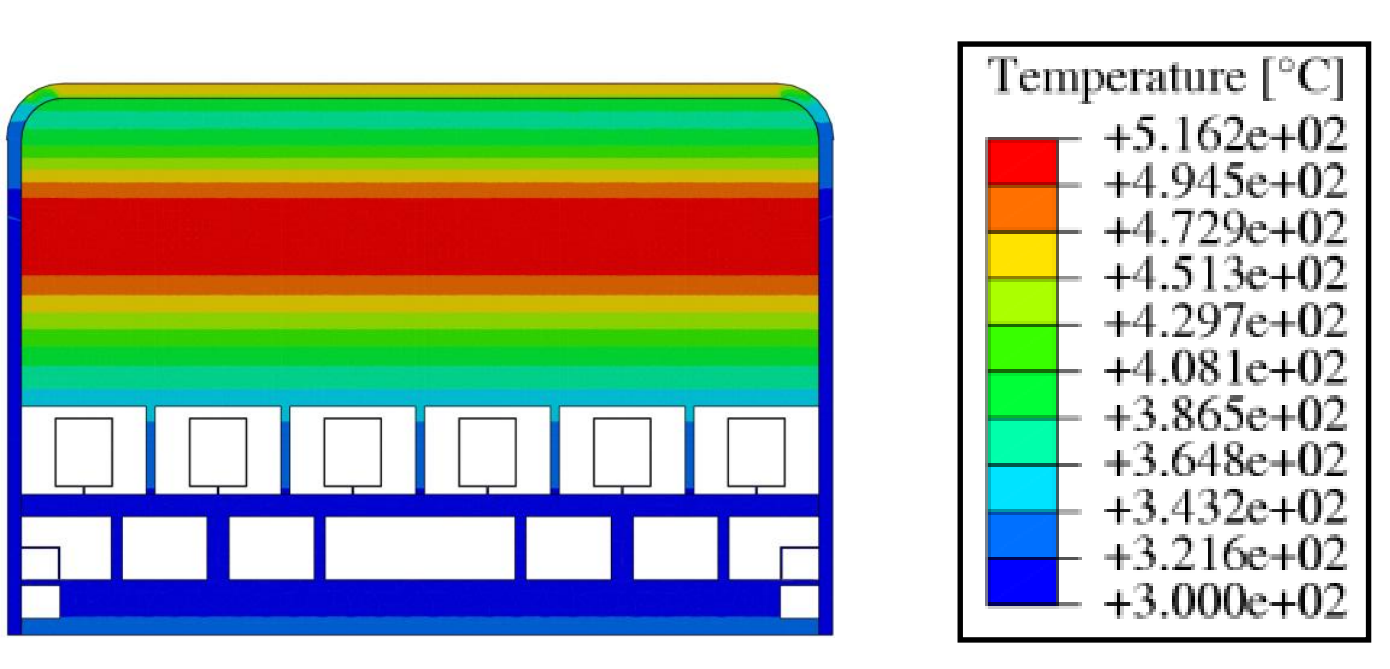

\section{Results}

- COB with Tungsten
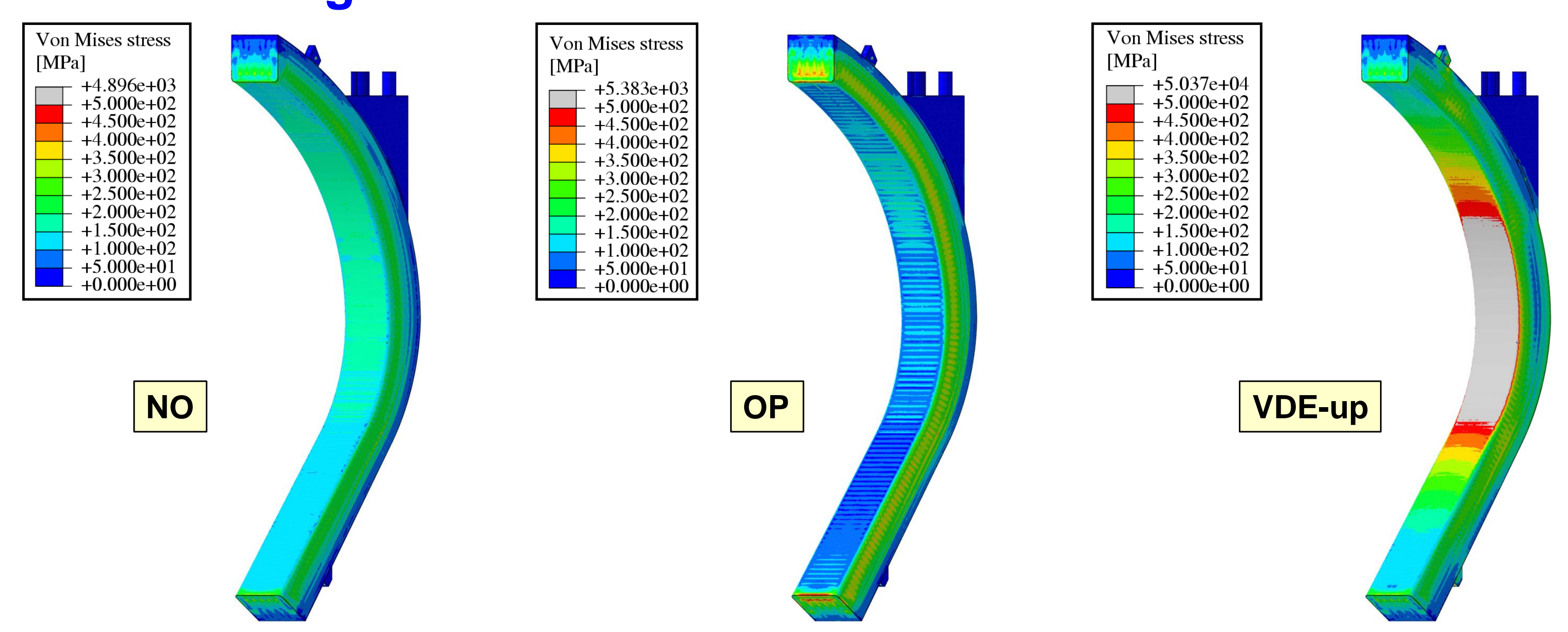

Deformed vs. Undeformed shape
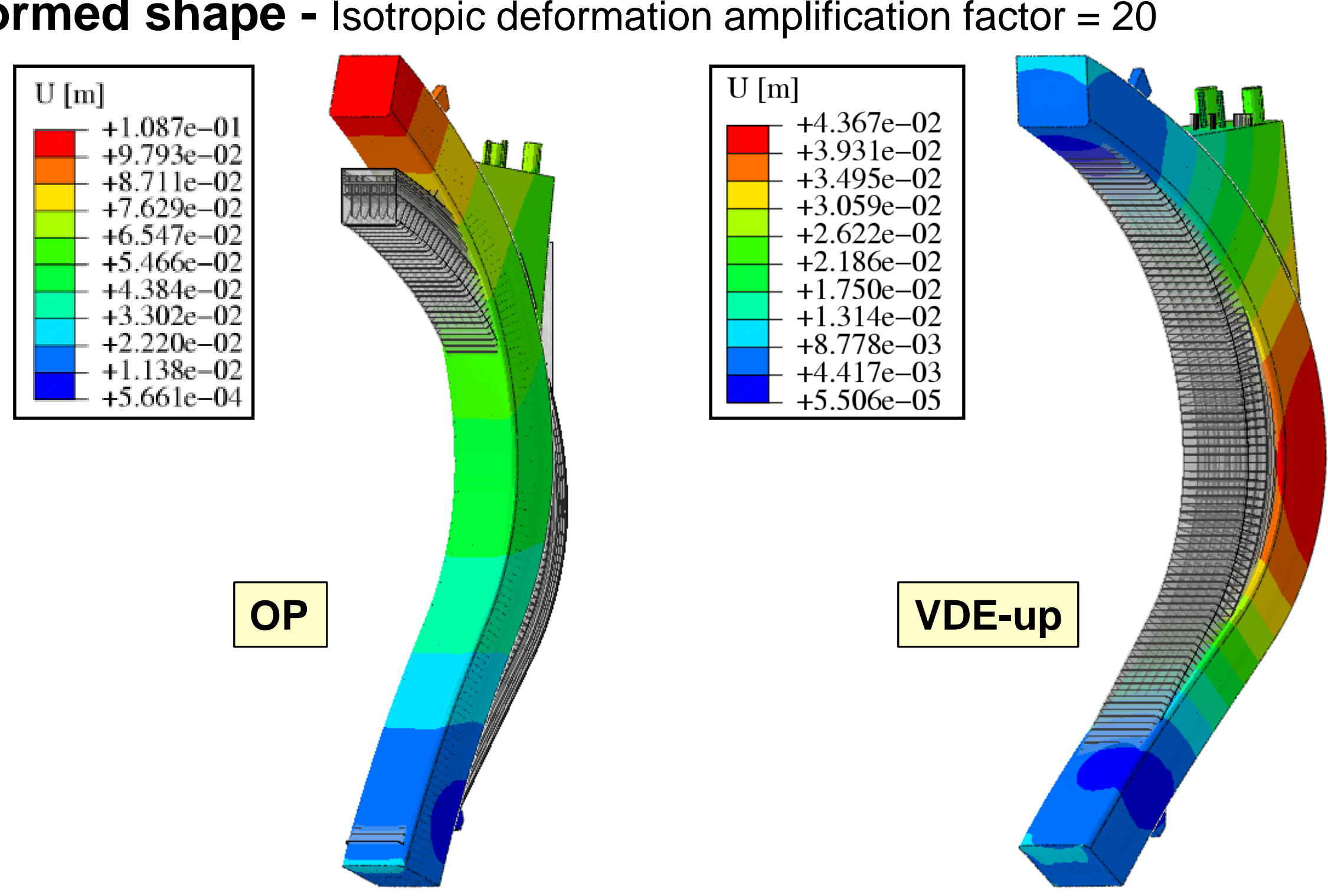

- COB without Tungsten
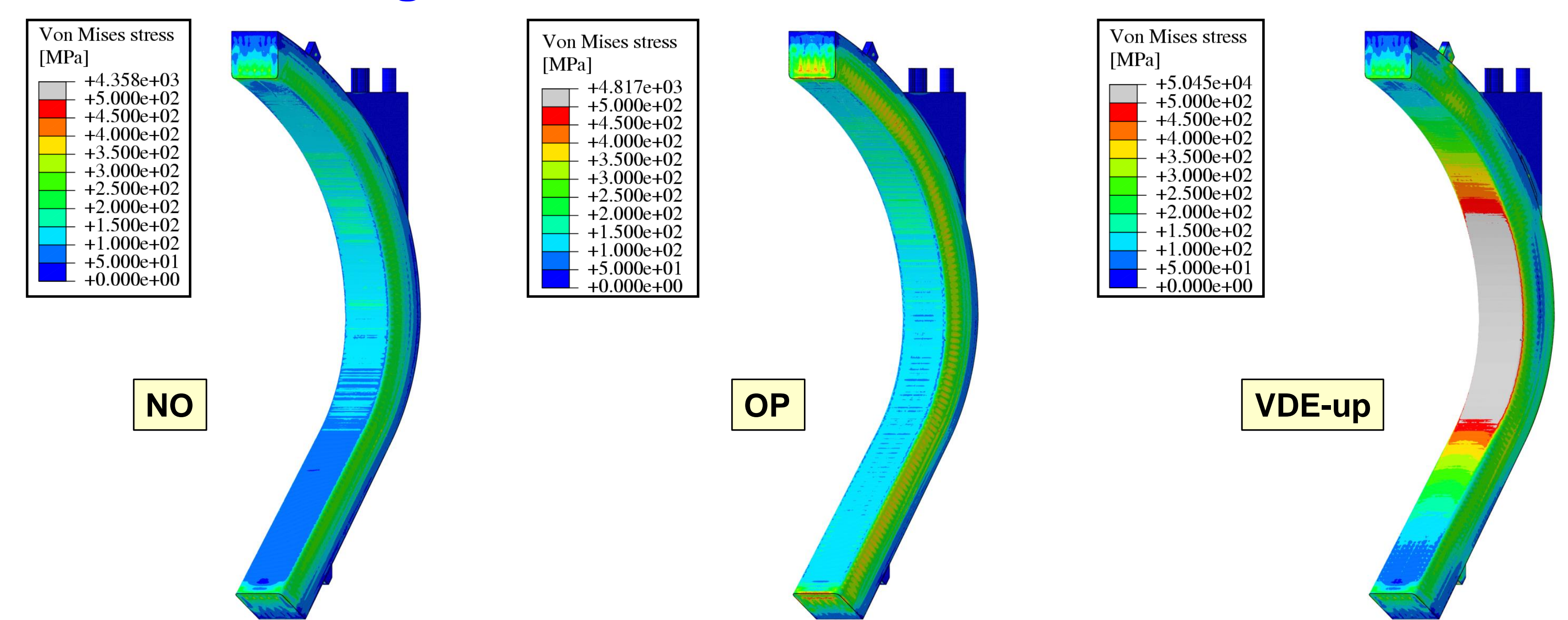

Deformed vs. Undeformed shape - Isotropic deformation amplification factor $=20$

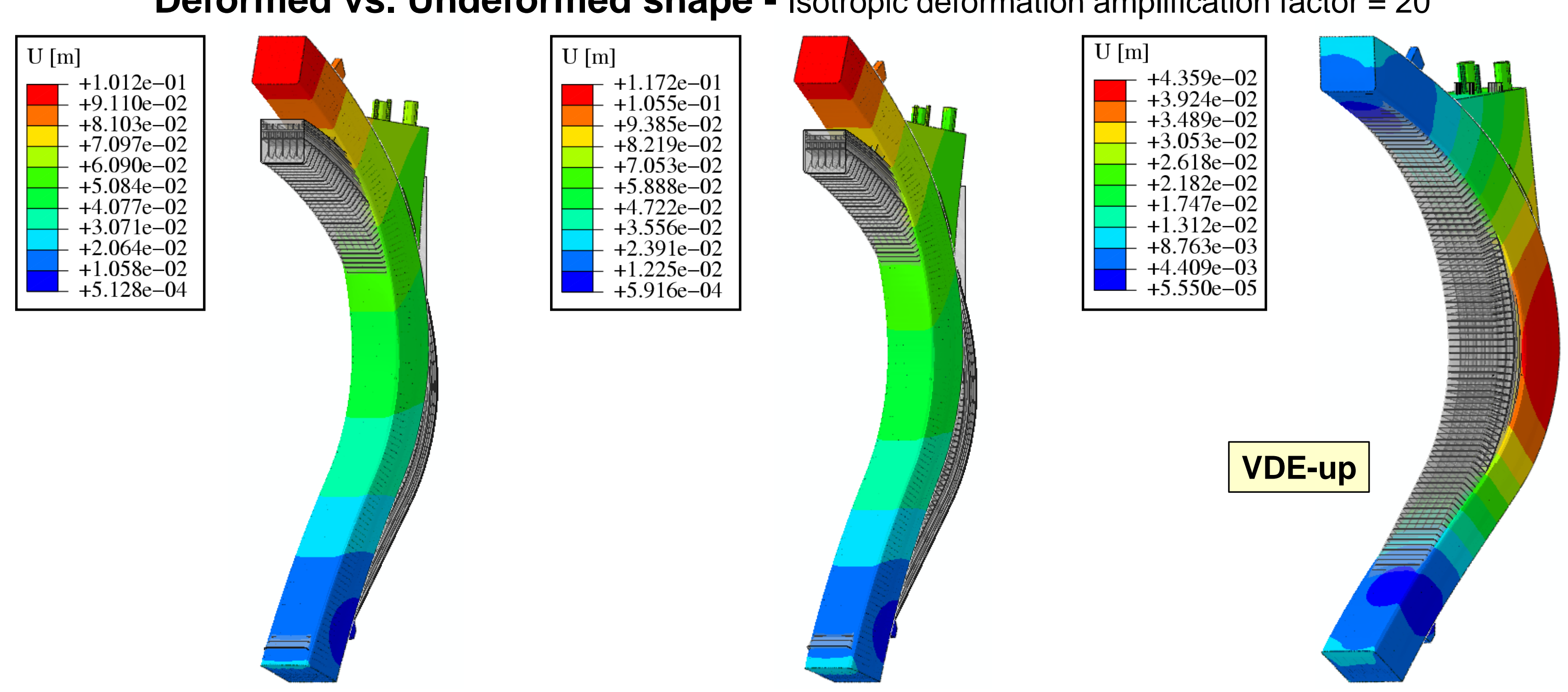

